\title{
PROPOSTA TEÓRICO-METODOLÓGICA PARA O ESTUDO DE SUJEITOS INFORMACIONAIS USUÁRIOS DE SITES DE REDES SOCIAIS VIRTUAIS
}

\author{
Ruleandson do Carmo Cruz $^{1}$ \\ Programa de Pós-graduação em Ciência da Informação da UFMG \\ ruleandson@gmail.com
}

\begin{abstract}
Resumo
Revisa os conceitos de sujeitos informacionais, práticas informacionais, redes sociais, e sites voltados à formação de redes sociais virtuais. Destaca a importância contemporânea dos sites de redes sociais no contexto informacional. Apresenta proposta teórico-metodológica para o estudo dos sujeitos informacionais usuários de sites de redes sociais e das práticas informacionais por eles performadas em tais sites. Considera a dificuldade de se encontrar modelos para o estudo social dos sujeitos em contexto virtual.
\end{abstract}

Palavras-chave: Sujeitos informacionais. Práticas informacionais. Redes sociais virtuais. Sites de redes sociais. Metodologia.

\section{EPISTEMOLOGICAL ASPECTS IN STUDIES ON DOMAIN ANALYSIS UNDER RATIONALISM AND EMPIRISM LENSES}

\begin{abstract}
This article aims to review the informational subject, informational practices, social networks and websites targeted to social network formation. It highlights the importance of contemporary social network websites. It aims to introduce a theoretical-methodological proposal for informational subjetc who are also users of social network study and informational practices used and related to them. It considers the obstacles to find models for social studies in a virtual context.
\end{abstract}

Keywords: Informational subject. Informational practices. Social networks. Social network websites. Methodology.

\section{INTRODUÇÃO}

Dos cerca de 7,4 bilhões de pessoas que vivem no mundo (CRIADO, 2016), pelo menos dois bilhões são usuários mensais do site voltado à formação de redes sociais virtuais Facebook e 800 milhões de pessoas nele curtem postagens diariamente - ação de demonstrar ter gostado da informação compartilhada por outro sujeito informacional usuário do referido site (AGÊNCIA BRASIL, 2017). Entretanto, o Facebook é apenas um, das dezenas de sites do tipo

\footnotetext{
${ }^{1}$ Pós-doutorando, jornalista servidor da Universidade Federal de Minas Gerais - UFMG e pesquisador do grupo de pesquisa EPIC - Estudos em Práticas Informacionais e Cultura da UFMG, formado pelo Centro Universitário de Belo Horizonte - UniBH, pós-graduado em Criação e Produção para Mídia Eletrônica pelo UniBH, mestre e doutor em Ciência da Informação pelo Programa de Pós-Graduação em Ciência da Informação da UFMG.
}

\section{(c) (i) (2)}

Esta obra está licenciada sob uma Licença Creative Commons Atribuição 4.0 Internacional (CC BY-NC-AS 4.0).

LOGEION: Filosofia da informação, Rio de Janeiro, v. 5 n. 1, p. 71-88, set.2018/fev. 2019 
existentes e nos quais sujeitos de diversas partes do planeta criam e socializam informações. $\mathrm{Na}$ contemporaneidade, o acesso a e a navegação em sites de redes sociais são as atividades mais comuns dos internautas mundiais (CISCO, 2017), sendo que, no Brasil, os sujeitos passam, em média, 650 horas por mês navegando em redes sociais (COMSCORE, 2015).

Diante desse cenário, no qual assume inquestionável importância a troca de informações em sites de redes sociais virtuais, tais sites tornam-se grande oportunidade de pesquisa no campo da Ciência da Informação - CI, em especial na subárea de estudos de usos e usuários da informação, para se entender as ações e práticas informacionais dos sujeitos no contexto virtual, investigando comunidades virtuais e temas discutidos online. Como frisa WiIdén-Wulff et al. (2008), a informação tem o poder de modificar a vida dos sujeitos:

\begin{abstract}
é pertinente estudar os propósitos para os quais as pessoas se ocupam usando um grupo como uma fonte de informação e analisar que problemas este uso resolve, que tipo de informação ele provê e quais qualidades do grupo são encontradas e que fazem diferença na vida das pessoas (WIDÉN-WULFF et al., 2008, p. 352, tradução nossa).
\end{abstract}

Analisando a troca de informações na Internet, Kleinberg e Lawrence (2001, p. 1850) dizem que a migração da comunicação e do comércio para a Internet é também uma alteração no fluxo informacional mundial. Para os autores, a $\mathrm{Web}$ torna-se terreno fértil para pesquisas, pois através das páginas criadas pelos usuários, de suas participações em sites e comunidades virtuais e dos fluxos informacionais por eles estabelecidos, a Web evidencia "o aparecimento de uma fração crescente de conhecimento humano e comunicação [...] oferecendo uma oportunidade sem precedentes para mapear e analisar interesses e relações dentro de sociedades" (KLEINBERG; LAWRENCE, 2001, p. 1850, tradução nossa).

Por isso, estudar os sujeitos informacionais usuários de sites voltados à formação de redes sociais virtuais é um desafio à $\mathrm{CI}$, dado que "o que torna a informação especialmente significativa na atualidade é a sua natureza digital” (CAPURRO; HJØRLAND, 2007, p. 149). É com a informação virtual e digital, e com a realidade virtual - "entendida como uma condição de interação, na qual a informação envolve e inclui o receptor através de uma maior condição de participação de sua percepção" (BARRETO, 1997, online) - a CI "redefine o conteúdo e a prioridade de seus objetivos continuamente", sendo que hoje a rede digital constitui um importante foco de estudo para a área (BARRETO, 1997, online). Com isso

A rede digital [...] cria novos problemas sociais, econômicos, técnicos, culturais e políticos, os quais mal começamos a enfrentar teórica e praticamente. Esse é, ao meu ver, o grande desafio epistemológico e epistemoprático que a tecnologia moderna apresenta a uma ciência da informação (CAPURRO; HJØRLAND, 2003, online).

Além disso, é fundamental à CI buscar entender o caráter fluido que a informação adquire nos espaços virtuais, assim como dedicar-se à importância de se entender a informação 
enquanto fenômeno subjetivo, gregário da cultura. Dito isso, para refletir e auxiliar no entendimento dos sujeitos informacionais usuários dos sites de redes sociais virtuais no campo da CI, o presente artigo apresenta proposta metodológica para o estudo qualitativo dos sujeitos e das práticas informacionais por eles performadas em tais sites. Trata-se de um modelo aberto que pode ser modificado de acordo com a empiria e as questões pesquisadas.

\section{SITES VOLTADOS À FORMAÇÃO DE REDES SOCIAIS VIRTUAIS}

Ao se estudar os sujeitos informacionais em sites voltados à formação de redes sociais virtuais faz-se indispensável conceituar: redes sociais virtuais, sites voltados à formação de redes sociais virtuais, sujeitos informacionais e práticas informacionais. Apresenta-se a seguir, sucintamente, definições dos referidos conceitos.

A Análise de Redes Sociais possui foco na interação como primado fundamental do estabelecimento das relações entre os atores que formarão as redes sociais, físicas e/ou virtuais, por isso ao analisar-se redes sociais virtuais faz-se obrigatória a existência de um locus onde a interação possa ocorrer e ocorra para que se possa falar em rede social virtual (RECUERO, 2004, p. 3-4). O locus focado neste artigo são os sites voltados à formação de redes sociais virtuais, nos quais os sujeitos informacionais formam redes sociais. Garton, Haythornthwaite e Wellman (1997, online) dizem que "quando um computador conecta pessoas ou organizações, isto é uma rede social" (tradução nossa). Nesse sentido,

\footnotetext{
As redes sociais ultrapassaram o âmbito acadêmico/científico, conquistando e ganhando espaço em outras esferas. E podemos observar esse movimento chegando a Internet e conquistando cada vez mais adeptos, aglutinando pessoas com objetivos específicos, ou apenas pelo prazer de trazer à tona ou desenvolver uma rede de relacionamentos (TOMAÉL; ALCARÁ; DI CHIARA, 2005, p. 95).
}

Para Wellman (2001, p. 2031), redes assistidas por computador são inerentemente redes sociais e instituições sociais, ligando pessoas, organizações e conhecimento, e não podem ser estudadas isoladamente, pois devem ser avaliadas como integradas à vida cotidiana. Segundo o autor, a Internet causa a proliferação de redes de solidariedade no trabalho e em comunidades, convívio social entre amigos e parentes fisicamente distantes, além de aumentar contatos importantes. De acordo com Wellman (2001), a popularização do e-mail na década de 1980 e da interação homem-computador, baseada no e-mail e na $W e b$, torna a sociedade atual a sociedade transmitida em rede.

Nessa mesma perspectiva, transpondo a metáfora de rede, usada para entender uma estrutura social, para o ambiente online, Recuero (2009a, p. 25) define rede social virtual como 
a "teia de conexões que espalham informações, dão voz às pessoas, constroem valores diferentes e dão acesso a esse tipo de valor [capital social]". Deste modo, a existência de redes sociais na Internet é possibilitada pela existência do

software social que, com uma interface amigável, integra recursos além dos da tecnologia da informação. $\mathrm{O}$ uso desses recursos gera uma rede em que os membros convidam seus amigos, conhecidos, sócios, clientes, fornecedores e outras pessoas de seus contatos para participar de sua rede, desenvolvendo uma rede de contatos profissional e pessoal, que certamente terá pontos de contatos com outras redes. Enfim, são ambientes que possibilitam a formação de grupos de interesses que interagem por meio de relacionamentos comuns (TOMAÉL; ALCARÁ; DI CHIARA, 2005, p. 95-96).

O referido software social, segundo Recuero (2004, p. 7), são "sistemas que visam proporcionar conexões entre as pessoas, gerando novos grupos e comunidades, simulando uma organização social”. Exemplos desses softwares sociais são os sites como Facebook, Twitter, Linkedin etc. entendidos por Cruz (2016) como sites voltados à formação de redes sociais virtuais, sites que evidenciam as redes formadas pelos sujeitos neles envolvidos e as trocas informacionais performadas por tais sujeitos.

De acordo com o Boyd e Ellisson (2007), os sites de redes sociais são:

serviços baseados na web que permitem aos indivíduos (1) construir um perfil público ou semi-público dentro de um sistema delimitado, (2) articular uma lista de outros usuários com quem compartilham uma conexão e (3) visualizar e atravessar sua lista de conexões e as feitas por outros dentro do sistema. A natureza e a nomenclatura dessas conexões podem variar de um site para outro [...] A grande diferença entre sites de redes sociais e outras formas de comunicação mediada pelo computador é o modo como permitem a visibilidade e a articulação das redes sociais (BOYD; ELLISSON, 2007, online, tradução nossa).

Para Warren (2007), três dimensões devem ser consideradas em relação às redes sociais na sociedade da informação:

\footnotetext{
a - temporalidade (comunicação em rede em tempo real, mas que permite a conexão de tempos sociais distintos);

$\mathrm{b}$ - espacialidade (criação de territorialidade de novo tipo, virtuais e presenciais, e a conexão entre ambas);

c - sociabilidade (novas formas de relações sociais, em intensidade, abrangência, intencionalidade e, em especial, seu significado e alcance num novo tipo de esfera pública) (WARREN, 2007, p. 37).
}

Acerca dos elementos das redes sociais virtuais, Recuero (2009b, p. 25-44) divide-os em: a) atores e b) conexões. Sobre os atores, a autora diz que em qualquer rede social os atores, representados na rede pelos nós, são as pessoas envolvidas na rede a qual se analisa. Tais atores formam e moldam as estruturas sociais, por meio da interação e constituição de laços sociais. Estas características não diferem muito o ator da rede social virtual do ator da rede social offline, sendo a principal característica do ator da rede social virtual o fato de ele ser uma representação do ator social físico, uma construção identitária na Internet. 
Um ator, assim, pode ser representado por um Weblog, por um fotolog, por um twitter ou mesmo por um perfil no Orkut. E, mesmo assim, essas ferramentas podem apresentar um único nó (como um Weblog, por exemplo), que é mantido por vários atores (um grupo de autores do mesmo blog coletivo) [...] São espaços de interação, lugares de fala, construídos pelos atores de forma a expressar elementos de sua personalidade ou individualidade (RECUERO, 2009b, p, 25-26).

Dessa maneira, a presença do ator da rede social virtual se dá por meio da apropriação de perfis em sites como o Twitter e o Facebook. Tais apropriações são "a presença do 'eu' no ciberespaço, um espaço privado e, ao mesmo tempo, público. Essa individualização dessa expressão de alguém 'que fala' através desse espaço é que permite que as redes sociais sejam expressas na Internet” (RECUERO, 2009b, p. 27). Com isso, os perfis criados por indivíduos e que os representam enquanto atores no ciberespaço são "pistas de um 'eu' que poderá ser percebido pelos demais. São construções plurais de um sujeito, representando múltiplas facetas de sua identidade" (RECUERO, 2009b, p. 30).

Como segundo elemento constituinte das redes sociais virtuais, Recuero (2009b, p. 30), aponta as conexões, compreendidas como os laços sociais formados por meio da interação social entre os atores, cujas variações alteram as estruturas da rede, e que somente são percebidos por meio dos rastros que um ator deixa no ciberespaço, como, por exemplo, comentários em um blog.

Entendidos os dois elementos, e tendo a interação sido estabelecida e os laços formados, os atores dos sites voltados à formação de redes sociais virtuais podem compartilham o capital social:

O conceito de capital social, entretanto, é variado e não há uma concordância, entre os estudiosos, sobre qual vertente deve ser seguida (p. 44-45) [...] consideramos o capital social como um conjunto de recursos de um determinado grupo (recursos variados e dependentes de sua função, como confirma Coleman [1988²]) que pode ser usufruído por todos os membros do grupo, ainda que individualmente, e que está baseado na reciprocidade (de acordo com Putnam [2000 3 ). Ele está embutido nas relações sociais (como explica Bourdieu [1983 $]$ ) e é determinado pelo conteúdo delas (Gyarmati \& Kyte, 20045; Bertolini \& Bravo, 20016). Portanto para que se estude o capital social dessas redes, é preciso estudar não apenas suas relações, mas, igualmente, o conteúdo das mensagens que são trocadas através delas. Esta ideia, baseada principalmente no conceito de Coleman (1988), mas com algumas ressalvas associadas a outros autores, parece ser a mais indicada para o estudo do capital social

\footnotetext{
${ }^{2}$ COLEMAN, J. S. Social Capital and the creation of Human Capital. American Journal of Sociology, n. 94, v. S95-S120, 1988.

${ }^{3}$ PUTNAM, R. D. Bowling Alone: The collapse and revival of American Community. New York: Simon e Schuster, 2000.

${ }^{4}$ BOURDIEU, P. The forms of Capital Social. Originalmente publicado em "Okonomisches kapital, kulturelles Kapital, soziales Kapital". In: Soziale Ungleichheiten (Soziale Welt, Sonderheft 2). Goettingen: Outto Schartz \& CO, 1983. Traduzido para o ingles por Richard Nice.

${ }^{5}$ GYARMATI, D. e KYTE, D. Social Capital, Network Formation and the Community Employment Innovation Project. In: Policy Research Iniciative, vol. 6, n. 3. Dosponível em: . Acesso em 04 maio de 2005.

${ }^{6}$ BERTOLINI, Sandra; BRAVO, Giácomo. Social Capital, a Multidimensional Concept, 2001. Disponível em . Acesso em: 17 out. 2004.
} 
nas redes sociais. Isso porque ela trabalha o caráter estrutural do capital social, sua capacidade de transformação de acordo com a função e sua base na reciprocidade, que consideramos os elementos essenciais do conceito (RECUERO, 2009b, p. 50).

Focando-se no aspecto informacional dos sites voltados à formação de redes sociais virtuais, Ribas e Ziviani (2008) observam que as redes de informação constituídas em redes sociais virtuais permitem os processos de produção, reedição e circulação da informação. Assim, tais redes informacionais podem ser de dois tipos: a) redes de informação relativamente formalizadas, como fóruns patrocinados, e b) redes de informação autodefinidas, como redes de comunicações interativas, espontâneas e organizadas ao redor de interesses ou objetivos comuns. Com isso, as autoras observam que tais redes que utilizam as Tecnologias da Informação e Comunicação - TICs em sua organização, como é o caso das redes sociais virtuais

o importante a ser destacado é o constante fluir de imagens, informações e mensagens que a rede possibilita, além de ser um espaço de transição, que permite a comunicação permanente, precisa e rápida entre os atores da cena mundial [...] uma maneira de constituir-se socialmente com grande potencial interativo (RIBAS; ZIVIANI, 2008, online).

Acerca da presença da informação nas redes sociais virtuais, Aguiar (2007) apresenta tipificações de tais redes a partir do fluxo de informações circulante em cada rede. Assim, a autora diz que além de o próprio conceito de redes sociais ser uma metáfora para uma estrutura social, desde que se iniciam os estudos de tais redes, são utilizadas várias metáforas de acordo com as dinâmicas e fluxos de informações das redes sociais para descrevê-las, como: malha, trama, árvore, teia e rizoma.

Falando sobre a rede social de informações do tipo árvore, a autora pondera que nela a informação

parte de uma 'raiz' e se difunde ou dissemina através de 'ramos' ou ramais, isto é, um processo comunicativo que se ramifica até um certo limite (se for 'podado') ou pode se desdobrar indefinidamente, com a agregação de novos integrantes", em um modelo no qual a produção é centralizada e a comunicação é do tipo de um para muitos (AGUIAR, 2007, p. 5).

Por sua vez, na rede social de informações do tipo malha ou trama, a rede é formada por "ligações simétricas entre os 'nós' [...] que pressupõem relações equidistantes de comunicação e fluxos regulares de informação; as mensagens fluem por 'contágio', de nó em nó [...] como na propagação de boatos", sendo o modelo da comunicação viral (AGUIAR, 2007, p. 5).

Enquanto isso, na rede social de informações do tipo teia, as relações desenvolvem-se a partir de uma liderança, de um facilitador do fluxo de informações, ou de um centro que distribua as mensagens recebidas de qualquer nó para todos os nós da rede, não havendo comunicação direta entre todos os nós e sendo o fluxo informacional dependente da distribuição 
das mensagens, que primeiro são enviadas ao nó central que a distribui aos demais (comunicação do tipo todos para um, um para todos), mas que pode não enviar para um ou alguns nós específicos (comunicação seletiva). Tal modelo é o mais utilizado em redes organizacionais e em listas de discussões virtuais (AGUIAR, 2007, p. 6).

Por fim, em relação aos tipos de rede, na rede social de informações do tipo rizoma, a rede é marcada pela

multiplicidade de relações assimétricas de comunicação, desencadeadas em vários pontos simultaneamente, e de fluxos centrados e não-regulares de informação (no tempo e no espaço), nos quais não é possível identificar um ponto gerador único [...] caracteriza-se pela multidirecionalidade: o fluxo de informações pode partir de qualquer ponto, ou de vários, e qualquer pessoa pode enviar mensagens para quem quiser, ou para todos, simultaneamente; os papéis de emissor e receptor são intercambiáveis; e a circulação de informação por toda a rede independe de uma instância central (AGUIAR, 2007, p. 6).

Sobre o papel dos atores e dos nós formados por eles em relação ao fluxo de informações nas redes sociais virtuais, Aguiar (2007, p. 7-8) diz haver nós ativos, nó focal e os atores isolados:

1) nós ativos - são os que mais frequentemente tomam a iniciativa da comunicação ou alimentam a rede de informações relevantes com maior frequência, podendo ser líderes de opinião, caso influenciem as atitudes dos indivíduos, de grupos ou de toda a rede;

2) nó focal - é o ator que recebe o maior fluxo de informações da rede, como o moderador, coordenador ou animador e os especialistas, tidos como vitais pela rede para a manutenção dos objetivos dela;

3) atores isolados - são aqueles que mantém um comportamento passivo na rede em relação ao fluxo de informações, pois apenas acompanham o fluxo, mas raramente participam das ações comunicativas.

Entendidos, objetivamente, os sites voltados à formação de redes sociais virtuais e o fluxo informacional neles existentes, aponta-se, a seguir, conceituações de sujeitos informacionais e práticas informacionais.

\section{SUJEITOS INFORMACIONAIS E PRÁTICAS INFORMACIONAIS}

Segundo Day (2011), é obrigatório ao campo da CI demarcar a morte do termo usuário da informação, pois ele é teoricamente inadequado para a devida compreensão dos aspectos sociais, culturais e físicos dos indivíduos e das relações dos sujeitos com os afetos e poderes de tais aspectos. Ademais, ao se pensar em usuário da informação, de acordo com o autor, priorizase a pesquisa que objetiva determinar causas e efeitos ao longo do processo de busca por 
informação. Desse modo, é preciso, mais do que isso, "visualizar sujeitos e objetos como coemergências mediadas através de co-determinações contextuais e por meio de zonas comuns de afetos mútuos [relacionais]" (DAY, 2011, p. 86, tradução nossa).

Nesse prisma, torna-se emergente na CI o conceito de sujeito informacional. É o aspecto informacional que diferencia o estudo social dos sujeitos, os observando enquanto sujeitos informacionais, "sujeito sociais que atuam sobre o conhecimento para gerar, receber, transferir, construir e socializar a informação" (FREIRE; AQUINO, 2000, p. 72). Por isso, o sujeito faz a mediação do real por meio da informação, informação que por sua vez media tanto as transações intersubjetivas quanto a auto-identidade do sujeito (DAY, 2014).

Com isso, o antes entendido apenas como usuário da informação é visto como sujeito informacional:

[...] se constitui ao ter uma posição no espaço socioinformacional concreto, perante a reflexão, análise e atuação na estrutura social sob uma crítica profunda, sendo ele um agente de informação de conjuntura social, como quem realiza um ato político, para denunciar que o status-quo contemporâneo requer uma reestruturação; a partir do sentimento de comunidade e do reconhecimento do outro (RENDÓN-ROJAS; GARCÍA-CERVANTES, 2012, p. 42, tradução nossa).

Assim, analisar o sujeito informacional amplia a análise em relação à ideia de usuário da informação, pois

os sujeitos informacionais não representam apenas uma evidência empírica (seres humanos se relacionando com documentos e informações) mas, sobretudo, se relacionam com um amplo campo de construção de diferentes 'objetos de pesquisa', isto é, maneiras distintas de se compreender esses indivíduos e suas relações. Ao mesmo tempo, esses 'sujeitos informacionais' acrescentam algo à ideia de 'sujeito'. Não se trata apenas de se estudar pessoas, sujeitos, em si, ou em seus aspectos sociais (como faz a Sociologia), subjetivos (como faz a Psicologia) ou culturais (como faz a Antropologia). Estudar os indivíduos no campo da Ciência da Informação significa perceber que existem indivíduos usando, buscando, sentindo falta ou disseminando informação, e que essas ações os constituem enquanto um tipo particular de sujeitos - justamente os sujeitos informacionais (ARAÚJO, 2013, online).

Também emergente no campo da CI, o conceito de práticas informacionais se opõe à ideia de comportamento informacional. No entendimento de Savolainen (2007), a prática informacional é uma alternativa crítica à ideia de comportamento informacional. De acordo com o autor, o conceito de comportamento informacional começa a ser utilizado no meio dos anos 1960 e populariza-se nos anos 1990, no entanto, é, geralmente, usado sem a reflexão de que o termo comportamento associa-se a à behaviorista Análise do Comportamento, do campo da Psicologia, concepção, não adequada ao estudo da informação, entendida enquanto constituinte das relações sociais.

Para Savolainen (2007), a ideia de prática informacional também nasce nos anos 1960, mas ainda é pouco usada no campo da CI, em comparação ao uso do conceito de comportamento 
informacional. Para Araújo (2007) e Araújo (2013), o conceito de prática informacional é advindo do conceito de prática usado pela etnometodologia - a investigação dos métodos pelos quais os indivíduos dão sentido às ações deles - e permite estudar os sujeitos informacionais considerando as facetas sociais e portanto coletivas da produção de conhecimento.

Com isso, Savolainen (2007) diz que "comparado com o modelo de comportamento informacional, o conceito de prática informacional adota como papel central os aspectos sociais e culturais enquanto fatores determinantes e qualificantes da busca por informação e compartilhamento de informação pelos sujeitos" (SAVOLAINEN, 2007, p. 125, tradução nossa).

Segundo Araújo (1998), Araújo (2001a) e Araújo (2001b), a informação é um dos elementos fundantes das práticas sociais, pois é por meio da informação que os sujeitos se comunicam, tomam conhecimento de direitos e deveres e também tomam decisões, em nível individual ou coletivo. Assim, as ações sociais enquanto práticas informacionais, são estabelecidas em circuitos comunicacionais mantidos pelas formações sociais dos sujeitos e nos quais tais sujeitos realizam ações de recepção, geração e transferência de informações.

Assim, para Araújo (2001b), acerca dos tipos de ações das práticas informacionais, elas se caracterizam do seguinte modo: a) recepção, ação de acesso e seleção de informação; b) geração, ação de reapropriação, no sentido de agregar algum valor à informação; c) transferência, ação de repassar, de compartilhar a informação. Ambos os processos se dão sempre no contexto de grupos sociais, pois a "informação é um operador de relação ou, ainda, um indicador de mediação que possibilita e é possibilitado pelas relações sociais" (ARAÚJO, 2001b, online).

Em tal perspectiva, Silva (2008) ressalta que a ideia de práticas informacionais é um entendimento mais apropriado ao estudo das ações e relações sociais dos sujeitos:

\footnotetext{
A análise do comportamento informacional nas pesquisas em estudos de usuários buscam quantificações e padronizações, determinando este comportamento com base em variáveis preestabelecidas. A prática, ao contrário, supõe os indivíduos como protagonistas das ações, e busca compreender os atos encobertos das interações e a atividade de dar significado aos objetos e símbolos informacionais (SILVA, 2008, p. 59).
}

Apesar da adequada apropriação dos termos práticas informacionais e sujeitos informacionais, eles ainda trazem dificuldades aos pesquisadores da área de estudos de usos e usuários da informação (nome ainda forte nos diversos tipos de estudos de comportamento e práticas informacionais no Brasil):

Uma das principais dificuldades para as pesquisas na perspectiva das práticas informacionais pelo paradigma social da CI é a escassez de modelos metodológicos para o estudo dos sujeitos informacionais, no contexto sóciohistórico e cultural 
investigado. Se na linha do comportamento informacional há diversos modelos, na abordagem social das práticas informacionais os trabalhos são emergentes e, por vezes, os pesquisadores fazem arranjos e triangulações que os permitam investigar os sujeitos informacionais de acordo com as questões levantadas (CRUZ, 2016, online).

Assim, no presente artigo apresenta-se uma ideia metodológica para o estudo dos sujeitos informacionais usuários de sites voltados à formação de redes sociais virtuais, em busca de ajudar a diminuir a referida escassez de modelos.

\section{PROPOSTA METODOLÓGICA PARA O ESTUDO DE SUJEITOS INFORMACIONAIS USUÁRIOS DE SITES DE REDES SOCIAIS VIRTUAIS}

Neste artigo, fala-se sobre pesquisa qualitativa. De acordo com Flick (2009, p. 16), a pesquisa qualitativa não possui modelos precisos, por isso, uma de suas principais características e necessidades é o princípio da adequação como orientador: "os métodos devem ser adequados àquela questão e devem ser abertos o suficiente para permitir um entendimento de um processo ou relação".

Assim como ocorre com a pesquisa qualitativa, a pesquisa em CI também não possui uma metodologia específica e deve atentar-se à adequação das estratégias metodológicas à problemática em estudo. Isso se dá pelo que aponta González de Gomez (2000, online), segundo a qual, a CI apresenta-se desde seu início "como conjunto de saberes agregados por questões antes que por teorias". Dessa forma, a autora observa que

\footnotetext{
Quando são abordadas as práticas e ações de informação [como na presente pesquisa], devemos usar estratégias comunicacionais seja para reconstruir a produção de sentido dos atores sociais, seja para construir e interpretar indicadores operacionalizados sobre produtos e resultados observáveis das ações de informação. O acesso comunicacional aos fenômenos culturais da informação requer estratégias metodológicas descritivas, interpretativas, próprias da antropologia, a sociolingüística, os estudos sociais da ciência, entre outras (GONZÁLEZ DE GOMEZ, 2000, online).
}

Por isso, ao estudar-se o estrato informacional relacionado à produção subjetiva da informação, como, por exemplo, a informação criada e compartilhada pelos sujeitos em sites voltados à formação de redes sociais virtuais, o objeto da CI deve ser considerado como a “construção de significado de segundo grau a partir das práticas e ações sociais de informação, que constituem seu domínio fenomênico” (GONZÁLEZ DE GOMEZ, 2000, online). Tendo tal foco, o pesquisador conseguirá tratar os dados coletados nos sites enquanto construção dos modos intersubjetivos de significação e da definição cultural e social de uma evidência de informação.

De acordo com Cruz (2016), 
Estudar a informação enquanto artefato cultural resultante da performance social e virtual dos sujeitos informacionais dos sites voltados à formação de redes sociais virtuais não é tarefa fácil. Primeiramente, porque o estudo científico da Internet em si é recente, especialmente o estudo de tais sites. Portanto, não há muitos caminhosmodelo a serem seguidos. Segundamente, porque os referidos sites são dinâmicos e extremamente mutáveis, em relação às políticas de privacidade e aos recursos dos sites em si - entendidos, no prisma informacional desta obra, enquanto possibilidades de performance informacional dos sujeitos (CRUZ, 2016, online).

Assim, o autor ressalta que durante o desenvolvimento das pesquisas dos sujeitos no contexto dos sites voltados à formação de redes sociais virtuais, o pesquisador precisa ficar atento à volatilidade das informações postadas pelos sujeitos em tais sites. Isso porque, devido ao tempo de realização de um estudo aprofundado, a coleta de dados pode ser uma etapa difícil, se não for iniciada com tempo hábil, pois enquanto a coleta não é realizada o fenômeno que chamou a atenção do estudioso pode ser perdido: "alguns ou todos os dados basilares de um estudo podem ter sido apagados ou a privacidade da informação (pública ou restrita a amigos ou a específicos grupos de amigos do sujeito) pode ser alterada (pelo site ou pelo sujeito), impossibilitando a coleta" (CRUZ, 2016, online).

Por causa das constantes mudanças às quais os sites em questão estão sujeitos os pesquisadores precisam ter clara uma estratégia metodológica para lidar com eventuais problemas e garantir coleta substancial que permita a análise devida do fenômeno em investigação. Dessa forma, o autor frisa que a coleta, mesmo se tratando de um estudo qualitativo, não pode ser um "vale-tudo": "O pesquisador precisa traçar um método qualitativo para dar conta de realizar a pesquisa, garantindo veracidade e confiabilidade científicas" (CRUZ, 2016, online).

Dito isso, apresenta-se na sequência as recomendações metodológicas de Cruz (2016) para a investigação social qualitativa das práticas informacionais de sujeitos informacionais usuários de sites voltados à formação de redes sociais. Exemplos da aplicação de tais recomendações, parcial ou integralmente, podem ser conferidas em algumas pesquisas, como: Cruz (2011); Cruz e Frota (2014) e Cruz (2014). Devido às limitações de espaço, aqui não se apresentam os resultados das supracitadas pesquisas.

Ao todo, são sugeridos oito passos pelo autor. São eles:

1) Origem social do fenômeno - buscar nas teorias a origem do fenômeno e/ou da situação que se investiga para se explicitar, assim, conflitos sociais e se desvendar a razão de uma situação ocorrer e para alcançar a resposta à pergunta: isso resulta do quê?. Para isso, sugere-se o uso da teoria-método das Representações Sociais de Moscovici (2007):

[...] um sistema de valores, idéias e práticas, com uma dupla função: primeiro, estabelecer uma ordem que possibilitará às pessoas orientar-se em seu mundo material e social e controlá-lo; e, em segundo lugar, possibilitar que a comunicação seja 
possível entre os membros de uma comunidade, fornecendo-lhes um código para nomear e classificar, sem ambiguidade, os vários aspectos de seu mundo e da sua história individual e social" (MOSCOVICI, 19767 , xiii apud DUVEEN, 2007, p. 21).

Segundo Medeiros (2007, p. 73), a teoria das representações sociais aplicada à CI contribui com os estudos de usuários, pois "oferece, a um só tempo, um arcabouço conceitual para compreender os processos de transferência de informação em um contexto social, como um modo de apreendê-lo".

Nesse mesmo prisma, Moscovici (2007) analisa a relação entre informação e representações sociais e diz que as pessoas comuns (não cientistas) costumam analisar o mundo de modos semelhantes, pois vivemos em um mundo social:

[...] isso significa que nós nunca conseguimos nenhuma informação que não tenha sido distorcida por representações 'superimpostas' aos objetos e às pessoas que lhes dão certa vaguidade e as fazem parcialmente inacessíveis [...] elas são apenas um elemento de uma cadeia de reação de percepções, opiniões, noções e mesmo vidas, organizadas em uma determinada sequência (MOSCOVICI, 2007, p. 33).

Assim, o autor sugere estudar um fenômeno social de modo a buscar a origem dele até a ancoragem dele na contemporaneidade, para se entender qual a origem da representação social do que se estuda, podendo assim se problematizar as questões de modo mais efetivo.

Descrito o primeiro passo para o estudo dos sujeitos informacionais no contexto dos sites voltados à formação de redes sociais virtuais, volta-se à apresentação dos passos metodológicos sugeridos por Cruz (2016):

2) Performance informacional - identificar as possibilidades de performance informacional permitidas aos sujeitos no ou nos sites em estudo, descrevendo quais opções os sites apresentam (personalização do perfil, tipo de informações que podem ser postadas, formas de interação etc.) para a correta interpretação das apropriações permitidas e práticas realizadas pelos sujeitos informacionais;

3) Cultura informacional - entender a cultura dos sujeitos em análise e as regras simbólicas de convivência virtual, em especial, o idioma próprio usado e apropriado por eles. Segundo Cruz (2016, online):

\begin{abstract}
Até mesmo o modo como os sujeitos escrevem as palavras não pode ser visto de modo ingênuo. Um "ahazou" pode fazer com que se coloque um sic (assim no original), indicando um erro ortográfico na escrita de "arrasou", mas trata-se de uma linguagem própria de uma comunidade, integrando a cultura informacional de um grupo de sujeitos e sendo uma ação social de distinção, uma forma de diferenciação em relação a outros grupos. Além disso, o pesquisador pode estudar um grupo de sujeitos e concluir que eles não se utilizam de vídeos de músicas para se comunicarem entre si ou que não gostam de tal tipo de informação audiovisual, no entanto, pode ser que o moderador de tal comunidade proíba tal tipo de postagem e nos perfis pessoais de cada sujeito eles postem muitos videoclipes, por exemplo (CRUZ, 2016, online).
\end{abstract}

\footnotetext{
${ }^{7}$ MOSCOVICI, Serge. Social Influence and Social Change, Londres: Academic Press, 1976.
} 
4) Triangulação - criar estratégias cruzadas de coletas de dados para se aproximar o máximo possível das representações sociais dos sujeitos, lembrar-se de que na Internet e em especial nos sites de redes sociais, os sujeitos são um sabonete molhado em queda e o pesquisador é a mão que tenta agarrá-lo a qualquer custo. Assim, é preciso coletar as informações que os sujeitos postam nos sites e as informações do perfil dos sujeitos - a fachada virtual principal que eles mantêm online. Desse modo:

\begin{abstract}
É valioso, portanto, contrastar as postagens dos sujeitos informacionais estudados com as opiniões deles em entrevistas qualitativas, a fim de encontrar contradições. Um sujeito pode postar em um site de rede sociais que é contra a homofobia, por exemplo, mas na entrevista dizer que os gays são promíscuos (ou vice-versa). Nas redes sociais, virtuais ou não, o sujeito pode representar uma fachada, por saber a qual plateia se dirige, enquanto que na entrevista, tendo o sigilo do nome e autoria da resposta garantido pelo pesquisador, ele pode dizer o que realmente pensa (ou o contrário) (CRUZ, 2016, online).
\end{abstract}

5) Informações públicas - coletar os dados em postagens públicas dos sujeitos e não identificar, na pesquisa, o nome de usuário de tais sujeitos, de modo a buscar não violar o direito à privacidade. Se a postagem é pública, qualquer pessoa com acesso ao site em questão e aos principais buscadores poderia localizá-la. É uma salvaguarda ética enquanto ainda não se tem definições mais claras em relação a estudos no contexto virtual. Além disso, mesmo que momentaneamente, devido à volatilidade das informações na Internet, fazendo isso o pesquisador permite que outros pesquisadores possam percorrer o mesmo caminho metodológico, dando credibilidade à pesquisa;

6) Observação não participante - analisar postagens dos sujeitos na Internet é uma forma de observação sociológica, por isso, evite a "observação participante", no sentido de não postar informações nas comunidades virtuais em estudo, pois isso pode alterar os fluxos informacionais e os resultados da análise. Sabendo que estão sendo investigados, os sujeitos podem mudar a fachada virtual que representam;

7) Critérios metodológicos claros - definir os critérios metodológicos gerais (qual tipo de informação dos sujeitos serão coletadas e por quê?) e coletar os dados o mais breve possível durante a pesquisa, pois a qualquer momento as políticas de privacidade dos sites voltados à formação de redes sociais virtuais podem ser modificadas e com isso você pode não conseguir recuperar os dados e/ou o sujeito pode editar uma postagem ou apagá-la. Assim, o autor aponta: “Como sugestão, salve cada postagem como PDF e como imagem. Faça também uma tabela para guiar a coleta e trace uma estratégia de coleta e análise para cada objetivo do estudo, prática comum em pesquisas" (CRUZ, 2016, online); 
8) Grafo de redes de fluxos informacionais - desenhar as redes com base nos fluxos de informações postadas publicamente pelos sujeitos, considerando informações criadas (autorais) ou compartilhadas pelos sujeitos informacionais e que definam os conceitos ou o conceito do que se estuda. Para o autor:

\begin{abstract}
Somente assim será possível dar voz às representações sociais dos sujeitos estudados e garantir a análise das visões deles e não da visão do pesquisador. Se você investiga as informações da representação social do amor pelos sujeitos, investigue como os sujeitos definem o que é o amor nos sites e depois compare as definições deles com o que diz a teoria, para buscar as origens de tais definições (CRUZ, 2016, online).
\end{abstract}

Apresentada a proposta de Cruz (2016) para o estudo dos sujeitos em sites de redes sociais, pondera-se algumas considerações.

\title{
5 CONSIDERAÇÕES FINAIS
}

A Internet é um recurso informacional vasto e que oferece ferramentas de comunicação e troca de fluxos informacionais cada vez mais presentes no dia a dia dos sujeitos informacionais. No entanto, ela é recente na história da humanidade e consequentemente o seu estudo também é recente na histórica científica. Para o estudioso que se aventura a estudar a informação em contexto virtual traz-se o grande problema da escassez de teorias e de métodos capazes de permitir a coleta e a interpretação dos dados de pesquisa, forçando-o a um exercício científico de criatividade metodológica constante.

O modelo apresentado por Cruz (2016) mostra-se adequado ao entendimento social e qualitativo da informação enquanto artefato cultural socializado pelos sujeitos informacionais envolvidos nos sites voltados à formação de redes sociais virtuais e ao estudo das práticas informacionais por eles performadas. Isso se dá porque trata-se de proposta flexível que permite o uso de teorias adequadas ao entendimento do fenômeno que cada pesquisador investigue e também de técnicas metodológicas que sejam escolhidas como mais adequadas às problemáticas de cada pesquisa.

Sugere-se, apesar disso, que o modelo seja visto de forma crítica por cada pesquisador, trazendo novas contribuições e que o campo de estudos de usos e usuários das informações dedique-se a revisões como a aqui apresentada, na busca por formas práticas de estudar o sujeito informacional enquanto ser social e as práticas informacionais enquanto evidenciadoras da cultual de tais sujeitos. 


\section{REFERENCIAS}

AGÊNCIA BRASIL. Facebook alcança marca de 2 bilhões de usuários. Agência Brasil, Brasília, 27 jun.2017. Caderno Internacional. Disponível em:

$<$ http://agenciabrasil.ebc.com.br/internacional/noticia/2017-06/facebook-alcanca-marca-de-2bilhoes-de-usuarios>. Acesso em: 14 jul. 2017.

AGUIAR, Sonia. Redes sociais na Internet: desafios à pesquisa. In: CONGRESSO BRASILEIRO DE CIÊNCIA DA COMUNICAÇÃO - INTERCOM, 30., 2007, Santos.

Anais... Santos: Intercom - Sociedade Brasileira de Estudos Interdisciplinares da Comunicação, 2007. Disponível em:

$<$ http://www.intercom.org.br/papers/nacionais/2008/resumos/R3-1977-1.pdf>. Acesso em: 12 dez.2017.

ARAÚJO, Eliany Alvarenga de. A construção social da informação: práticas informacionais no contexto de Organizações Não-Governamentais/ONGs brasileiras, 1998.

221 f. Tese (Doutorado em Ciência da Informação) - Universidade de Brasília, Brasília, 1998.

ARAÚJO, Eliany Alvarenga de. Informação, sociedade e cidadania: práticas informacionais de organizações não governamentais - ONGs brasileiras. Informação \& Informação, Londrina, v. 6, n. 1, p. 31-54, jan./jun. 2001a. Disponível em:

$<$ http://www.uel.br/revistas/uel/index.php/informacao/article/view/1683/1434>. Acesso em 01 nov. 2013.

ARAÚJO, Eliany Alvarenga. A construção social da informação: dinâmicas e contextos. DataGramaZero, v. 2, n. 5, p. A03-0, 2001b. Disponível em:

$<$ http://www.brapci.inf.br/v/a/1246>. Acesso em: 12 dez. 2017.

ARAÚJO, Carlos Alberto Ávila. O sujeito informacional no cruzamento da Ciência da Informação com as Ciências Sociais. In: Encontro Nacional de Pesquisa em Ciência da Informação, 14. , 2013, Florianópolis. Anais... Florianópolis, 2013. Disponível em: $<$ http://enancib.sites.ufsc.br/index.php/enancib2013/XIVenancib/paper/viewFile/142/263>. Acesso em: 01 nov. 2013.

BARRETO, Aldo de Albuquerque. Perspectivas da Ciência da Informação. Revista de Biblioteconomia de Brasília, Brasília, v. 21, n. 2, 1997. Disponível em: $<$ http://www.brapci.inf.br/v/a/2620>. Acesso em: 12 dez. 2017.

BOYD, Danah M.; ELLISON, Nicole B. Social network sites: definition, history, and scholarship. Journal of Computer-Mediated Communication, Washington, v. 13, n. 1, 2007. Disponível em: <http://onlinelibrary.wiley.com/doi/10.1111/j.1083-

6101.2007.00393.x/full>. Acesso em: 14 jul. 2017.

CAPURRO, Rafael; HJØRLAND, Birger. O conceito de informação. Perspectivas em Ciência da Informação, Belo Horizonte, v. 12, n. 1, p. 148-207, jan./abr. 2007. Disponível em: <http://portaldeperiodicos.eci.ufmg.br/index.php/pci/article/view/54/47>. Acesso em: 12 dez. 2017.

CAPURRO, Rafael; HJØRLAND, Birger. The concept of information. In: CRONIN, Blaise (ed.). Annual review of information science and technology - Arist. v. 3. Medford, NJ: 
American Society for Information Science and Technology, 2003. p. 343-411. Disponível em: $<\mathrm{http}: / /$ www.capurro.de/infoconcept.html $>$. Acesso em: 30 Ago. 2008.

CISCO. The zettabyte era: trends and analysis. Cisco, Solutions, Write pappers, 7 jun. 2017. Disponível em: $<$ http://www.cisco.com/c/en/us/solutions/collateral/service-provider/visualnetworking-index-vni/vni-hyperconnectivity-wp.html>. Acesso em 14 jul. 2017.

COMSCORE. Futuro digital em foco 2015. ComScore, 2015. Disponível em:

$<$ https://www.comscore.com/por/Insights/Apresentacoes-e-documentos/2015/Futuro-DigitalGlobal-em-Foco-2015>. Acesso em 12 dez. 2017.

CRIADO, Miguel Ángel. 10 bilhões de pessoas povoarão a Terra em 2053. EI País, Caderno Ciência, Brasil, 25 ago. 2016. Disponível em:

$<$ https://brasil.elpais.com/brasil/2016/08/25/ciencia/1472108333_340880.html >. Acesso em: 14 jul. 2017.

CRUZ, Ruleandson do Carmo. Redes sociais virtuais de informação sobre amor: comportamento e cultura informacional de usuários do Orkut, 2011. 320 f. il. : enc. Dissertação. (Mestrado em Ciência da Informação) - Universidade Federal de Minas Gerais, Escola de Ciência da Informação, Belo Horizonte, 2011. Disponível em:

$<$ http://ruleandson.blogspot.com/2011/06/redes-sociais-virtuais-de-informacao.html $>$. Acesso em: 18 jun. 2018.

CRUZ, Ruleandson do Carmo. FROTA, Maria Guiomar da Cunha. "Orkutização do Lattes": cultura informacional e distinção. DataGramaZero - Revista de Informação, v. 15, n. 1, fev. 2014. Disponível em: < http://ruleandson.blogspot.com/2014/03/orkutizacao-do-lattescultura.html $>$. Acesso em: 20 fev. 2014.

CRUZ, Ruleandson do Carmo. Cultura informacional e distinção: a orkutização sob o olhar social da Ciência da Informação / Ruleandson do Carmo Cruz. - 2014. 228 f: il., enc. Tese. (Doutorado em Ciência da Informação) - Universidade Federal de Minas Gerais, Escola de Ciência da Informação, Belo Horizonte, 2014. Disponível em:

$<$ http://ruleandson.blogspot.com/2014/11/cultura-informacional-e-distincao.html $>$. Acesso em: 18 jun. 2018.

CRUZ, Ruleandson do Carmo. Preconceito social na Internet: cultura informacional e distinção em redes sociais. Belo Horizonte: do autor, 2016, v.1. Disponível em:

$<$ https://drive.google.com/file/d/0B8ZCmCe93ezzaUQtbGtVWlhTWU0/view >. Acesso em: 12 dez. 2017.

DAY, Ronald E. Death of the user: reconceptualizing subjects, objects, and their relations. Journal of the American Society for Information Science and Technology, Silver Spring, v. 62, n. 1, p. 78-88, 2011.

DAY, Ronald E. Indexing it all: the modern documentary subsuming of the subject and its mediation of the real. In: iConference 2014, 9, 2014, Berlim. Anais... Berlim. Disponível em: $<$ https://www.ideals.illinois.edu/bitstream/handle/2142/47318/140_ready.pdf?sequence=2>. Acesso em: 11 jul. 2017.

DUVEEN, Gerard. Introdução: O poder das ideias. In: MOSCOVICI, Serge. Representações sociais: investigações em psicologia social. Rio de Janeiro: Vozes, 2007. p. 7-28. 
FLICK, Uwe. Desenho da pesquisa qualitativa. Porto Alegre: Artmed, 2009.

FREIRE, Bernadina Maria Juvenal; AQUINO, Mirian de Albuquerque. Ciência da Informação: buscando abrigo para um sujeito. TransInformação, Campinas, v. 12, n. 2, p. 71-79, jul./dez. 2000. Disponível em: <http://periodicos.puccampinas.edu.br/seer/index.php/transinfo/article/view/1532/1506>. Acesso em: 11 jul. 2017.

GARTON, Laura; HAYTHORNTHWAITE, Caroline; WELLMAN, Barry. Studying online social networks. Journal of Computer-Mediated Communication, v. 3, n. 1, 1997. Disponível em: <http://onlinelibrary.wiley.com/doi/10.1111/j.10836101.1997.tb00062.x/full>. Acesso em: 12 dez. 2017.

GONZÁLEZ DE GOMEZ, Maria Nélida. Metodologia de pesquisa no campo da Ciência da Informação. Data Grama Zero - Revista de Ciência da Informação, v. 1, n. 6, dez. 2000. Disponível em:

$<$ http://www.repositorio.ufba.br:8080/ri/bitstream/ri/2393/1/DataGramaZero\%20\%20Revista\%20de\%20Ci\%C3\%AAncia\%20da\%20Informa\%C3\%A7\%C3\%A3o.pdf>. Acesso em 12 dez. 2017.

KLEINBERG, Jon; LAWRENCE, Steve. The structure of the Web. Science, v. 294, p. 18491890, nov. 2001.

MEDEIROS, Manoela Martins de. Informação e representações sociais: um estudo com familiares portadores de sofrimento mental. Encontros Bibli: Revista Eletrônica de Biblioteconomia e Ciência da Informação, Florianópolis, n. 24, p. 72-91, $2^{\circ}$ sem. 2007. Disponível em: $<$ http://www.periodicos.ufsc.br/index.php/eb/article/view/423/454>. Acesso em 4 fev. 2010.

MOSCOVICI, Serge. O fenômeno das representações sociais. In: _. Representações sociais: investigações em psicologia social. Rio de Janeiro: Vozes, 2007. p. 29-109.

RECUERO, Raquel da Cunha. Redes sociais na Internet: considerações iniciais. In: ENCONTRO DOS NÚCLEOS DE PESQUISA DA XXVII INTERCOM, 4., 2004, Porto Alegre. Anais... Porto Alegre. Disponível em: $<$ http://www.bocc.ubi.pt/pag/recuero-raquelredes-sociais-na-internet.pdf $>$. Acesso em 12 dez. 2017.

RECUERO, Raquel da Cunha. Redes sociais. In: SPYER, Juliano (org.). Para entender a Internet: noções, práticas e desafios da comunicação em rede. São Paulo: Não Zero, 2009a. Disponível em: https://para-entender-a-internet.softonic.com.br/. Acesso em: 12 dez.2017.

RECUERO, Raquel da Cunha. Redes sociais na Internet. Porto Alegre: Sulina, 2009b.

RENDÓN-ROJAS, Miguel Ángel; GARCÍA-CERVANTES, Alejandro. El sujeto informacional en el contexto contemporáneo. Un análisis desde la episte mología de la identidad comunitaria-informacional. Encontros Bibli: revista eletrônica de biblioteconomia e ciência da informação, Florianópolis, v. 17, n. 33, p. 30-45, jan./abr. 2012. Disponível em: <https://periodicos.ufsc.br/index.php/eb/article/view/15182924.2012v17n33p30/21709>. Acesso em: 11 jul. 2017.

RIBAS, Cláudia S. da Cunha; ZIVIANI, Paula. Redes de informação: novas relações sociais. Revista de Economía Política de las Tecnologias de La información y comunicación, Sergipe, v. 10, n.1, jan./abr. 2008. Disponível em: 
$<$ https://docs.google.com/viewer? $\mathrm{a}=\mathrm{v} \&$ pid=forums\&srcid=MTE1ODk0MzkzMzYwOTYyNj E5NjYBMTQ5Nzc1MDEwODIwNjA4MjE0NjIBU2FDQ1JtSGtJWkVKATAuMQEBdjI\&au thuser $=0>$. Acesso em: $12 \mathrm{dez} .2017$.

SAVOLAINEN, Reijo. Information behavior and information practice: reviewing the "umbrella concepts" of information-seeking studies. Library Quarterly, Chicago, v. 77, n. 2, p. 109-132, 2007.

SILVA, Ronaldo Alves da. As práticas informacionais das profissionais do sexo da zona boêmia de Belo Horizonte. 2008. 169 f. Dissertação (Mestrado em Ciência da Informação) Escola de Ciência da Informação, Universidade Federal de Minas Gerais, Belo Horizonte, 2008. Disponível em: <http://www.bibliotecadigital.ufmg.br/dspace/handle/1843/ECID7NXHYA>. Acesso em: $12 \mathrm{dez} .2017$.

TOMAÉL, Maria Inês; ALCARÁ, Adriana Rosecler; DI CHIARA, Ivone Guerreiro. Das redes sociais à inovação. Ciência da Informação, Brasília, v. 34, ed. 2, p. 93-104, maio/ ago. 2005. Disponível em: <http://revista.ibict.br/ciinf/article/view/1094/1206> . Acesso em: 12 dez.2017.

WARREN, Ilse Scherer. Redes Sociais: trajetórias e fronteiras. In: DIAS, Leila Chistina; SILVEIRA, Rogério Leandro Lima da (org.). Redes, sociedades e territórios. Santa Cruz do Sul: Unisc, 2007. p. 29-50.

WELLMAN, Barry. Computer networks as social networks. Science, Nova Iorque, v. 293, p. 2031-2034, set. 2001.

WIDÉN-WULFF, Gunilla; EK, Stefan; GINMAN, Mariam; PETIILÄ, Reija; SÖDERGÄRD, Pia; TÖTTERMAN, Anna-Karin. Information behaviour meets social capital: a conceptual model. Journal of Information Science, n. 34, v. 3, p. 346-355, 2008. 